\title{
VOLUMETRIC VisUALIZATION: AN EFFECTIVE UsE OF GIS TECHNOLOGY IN THE FIELD OF OCEANOGRAPHY
}

by T.O. Manley and James A. Tallet

"I have the impression that much more time is being spent in collecting data than in looking at it and analyzing it."

David Packard

Welcoming Remarks at

The Oceanography Society's Inaugural Meeting

$\mathrm{T}$ HE INFORMATION EXPLOSION that has swept the scientific community has created tremendous opportunities for expanding our understanding of the world. Vast amounts of available data offer new challenges for oceanographers, not only in discerning the complex relationships before them. but, just as importantly, in finding ways of conveying this newfound knowledge to colleagues and to the public. Much of this data, including ocean-bottom bathymetry or data obtained via satellite imagery, can be represented through the use of two- or pseudo threedimensional imagery. An even greater amount of information, however, does not lend itself to such graphic display and standard interpretation practices. These data sets represent complex three- and four-dimensional information obtained from computer models, advanced data gathering techniques and the synthesis of historical data bases. Fortunately, the technological advances that have produced this information avalanche have also produced new tools for managing and understanding this data. Specifically, Geographic Information System (GIS) applications that handle full three-dimensional property modeling. volumetric visualization, and quantitative analysis. such as Interactive Volume Modeling (IVM) , are well suited for the interpretation of such complex data sets.

Only thirty years ago, the amount of data collected from a series of deep ocean casts during a hydrographic cruise would have fit into a thin folder. The spatial orientation (typically gathered along pre-

T.O. Manley. Middlebury College, Department of GeologyScience Center, Middlebury, VT 05753-6151; James A. Tallet, Dynamic Graphics, Inc., 2855 Telegraph Avenue, Suite 405. Berkeley, CA 94705. determined linear tracks), as well as the intrinsic simplicity of these data sets, lend themselves to planar (cross sectional and/or plan view) mapping with a good, sharp pencil, a few sheets of paper, and an oceanographer's experience. By today's standards, it is quite common for field programs to generate over four orders of magnitude more information. Additionally, current scientifically-driven methodologies of oceanographic cruises often require detailed and repeated hydrographic mapping of discrete oceanographic features (such as rings and fronts), producing dimensionally (two, three and four) complex data sets. These mountains of information, which must be managed and analyzed, are growing at unforeseen rates in the oceanographic community and yet the primary display technique is still the hand drawn or computer produced two-dimensional contour map. Techniques are available for stacking several independently produced planar grids to create pseudo three-dimensional images, but they fall short of representing the spatial relationships of the data because they ignore the vertical or horizontal connectivity of the data. With the use of true three-dimensional or volumetric property modeling. these failings are overcome.

The expansion of standard two-dimensional gridding algorithms to full three-dimensional space enables information to be shared along the finite number of spatial planes within a specific volume, thereby producing a more accurate representation of the spatial variation of the property (e.g., salinity, temperature or chemical concentration) being investigated. Once calculated, the display of these models offers its own set of challenges. Since no single view can reveal the spatial relationships within the volume, techniques must exist to interactively manipulate the model. Through the use of graphic worksta- 


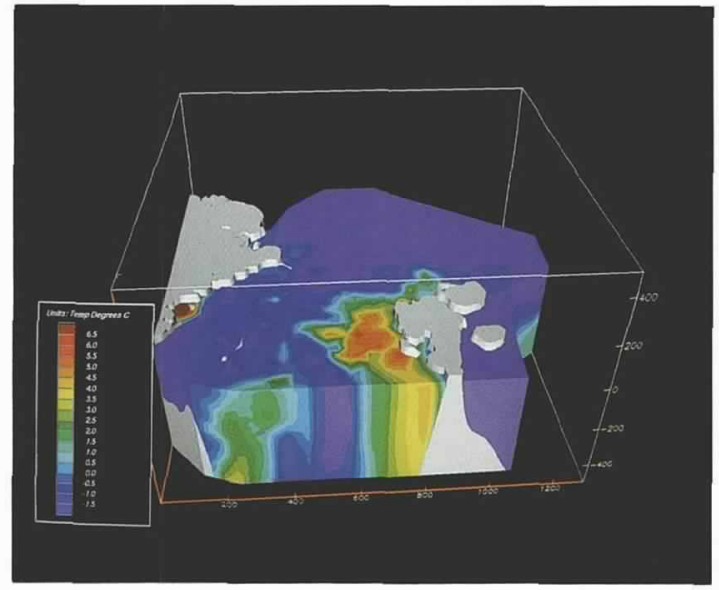

$a$.

Fig. 1: Oblique views of the 11-year mean temperature field in Fram Strait in the upper $500 \mathrm{~m}$. Horizontal distances $(\mathrm{km})$ are measured from an arbitrary origin. Temperature ranges are defined by the color key. Figs. Ia-1c show the effect of removing horizontal slices from the modeled volume to reveal the internal structure at depths of 0,200 and $367 \mathrm{~m}$ respectively. Red and orange colors define the warmer Atlantic inflow as the West Spitsbergen Current, while blue and purple colors indicate the polar waters exiting the Arctic Ocean from the north, as well as the northern extension of the Greenland Sea gyre.

tions and three-dimensional GIS applications such as IVM (used to generate the examples for this article), one is able to reveal the internal structure of the model by slicing along any one or any combination of the principal axes, by peeling away iso-valued shells (three-dimensional equivalent of contour lines), and by rotating the model in real time. These techniques allow researchers to visualize all aspects of the model and therefore gain a more thorough understanding of the represented physical environment.

The visualization of three-dimensional models offers one means of studying and understanding data characteristics. Quantitative analysis of the models provides another. Sophisticated mathematical operations are used to accurately calculate volumes as well as heat or salt content of specific features or water masses. The back interpolation of property values from one model along a specific surface allows researchers to examine the relationship between two properties of an individual water mass or model (e.g., determining the salt concentration at a particular temperature or density interface). Combining quantitative analysis with visualization of three-dimen-

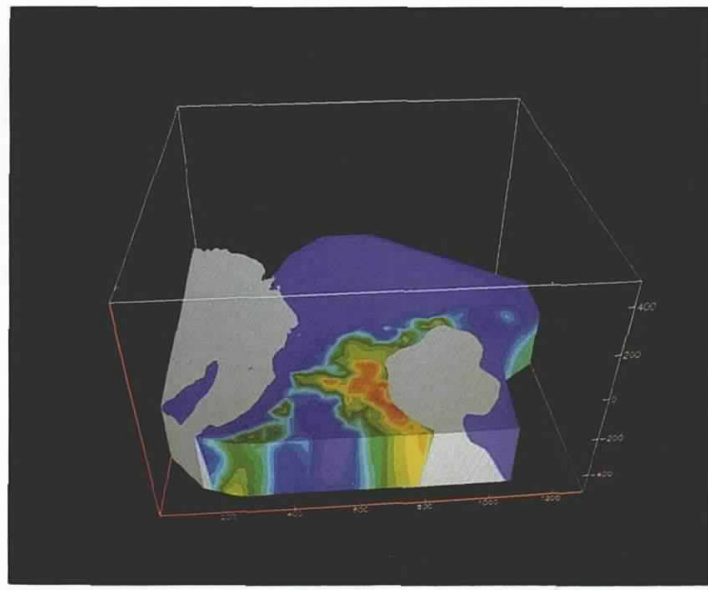

$b$.

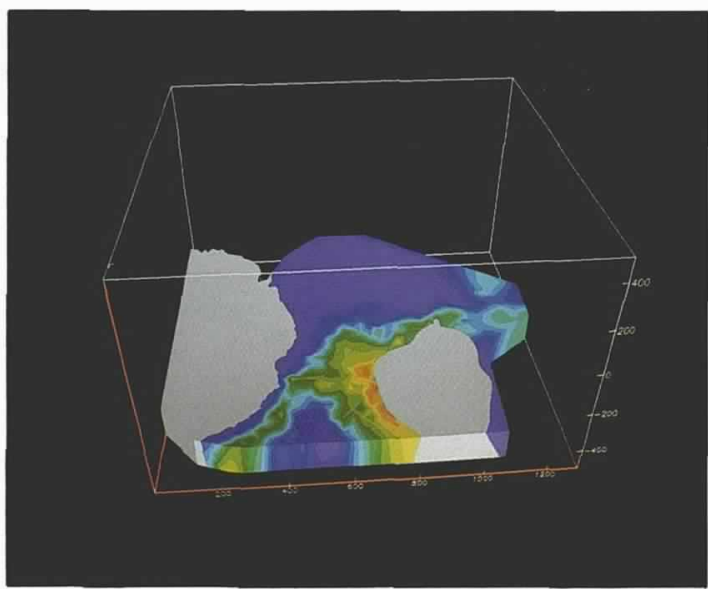

$c$.

sional models becomes a powerful tool for studying and comprehending our three-dimensional environment.

Examples of volumetric modeling that encompass a variety of temporal and spatial scales range from an 11-year data set obtained within a $1300 \mathrm{~km}$ by 1200 $\mathrm{km}$ region east of northern Greenland (Fram Strait) to near-synoptic mapping of mesoscale features at the marginal ice zone (MIZ). Within the narrative of the individual data sets and their corresponding images, attention is given to the location and nature of the original data, characteristics of the calculated models, manipulations used to produce the individual figures, as well as the resulting features and formulated concepts.

The large-scale Fram Strait data set (see back cover) represents a melding of 4,238 CTD (conductivity, temperature and depth) stations obtained between the years 1977 and 1987. The region was subdivided into $20 \mathrm{~km}$ by $20 \mathrm{~km}$ cells. Within each cell, all profiles of salinity, temperature and density were averaged and sub-sampled every $5 \mathrm{~m}$ vertically to a maximum depth of $500 \mathrm{~m}$. Many cells were without 


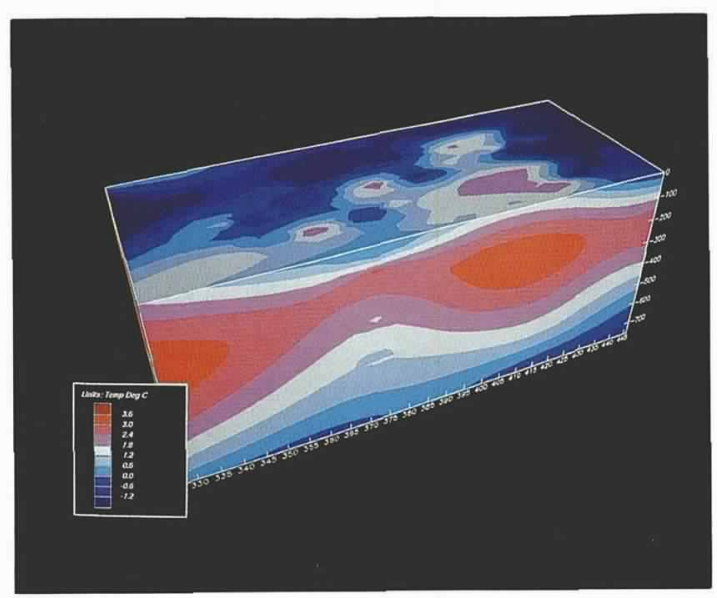

a.

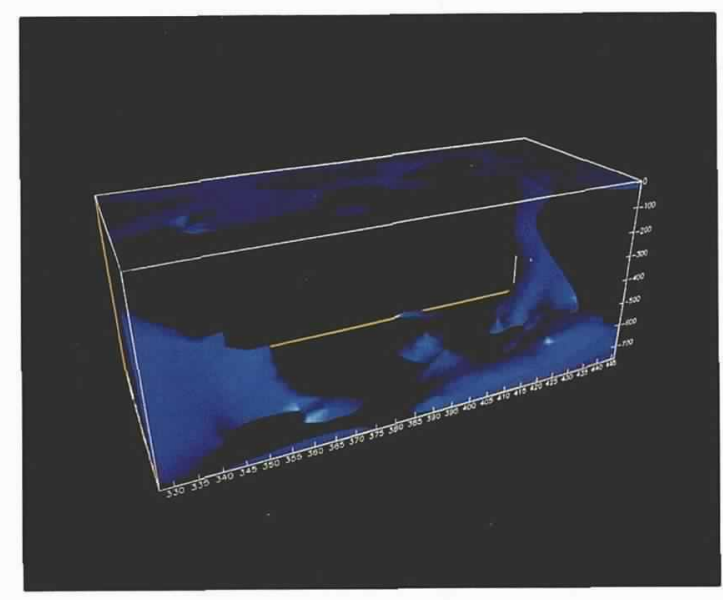

c.

Fig. 2: Modeled volume of temperature obtained from an intensive 36-hour XBT (expendable bathythermograph) and hull-mounted temperature survey of the marginal ice zone (MIZ) during the April-May phase of the 1989 CEAREX field program. Dark blues define polar waters while reddish colors define the warmer recirculated waters of Atlantic origin. Fig. 2 a shows one view of the entire modeled volume with color key at lower left. Fig. $2 b$ shows the $Y$-Z plane nearly face-on with all water warmer than $1.8^{\circ} \mathrm{C}$ removed. Data lines were superimposed onto this image as well as onto Fig. $2 d$ to show the density of observations. The amount of water removed in Fig. 2 a was calculated to be $1648 \mathrm{~km}^{3}$. Fig. $2 \mathrm{c}$ shows only the coldest water $\left(<0{ }^{\circ} \mathrm{C}\right)$ and an observed "chimney" of cold water that reaches the surface (back right). The vertical data lines superimposed on Figs. $2 b$ and $2 d$ may be toggled on and off with a single keystroke.

data while others possessed an abundance of information. Volumetric gridding of the resulting mean scattered data set was accomplished on a grid structure of 42 by 39 in the horizontal and 35 in the vertical. Bottom bathymetry and continental outlines (contoured from digitized data) were used to "clip" the gridded volume to remove regions not occupied by the ocean. Regions that represented excessive extrapolations were also removed by user-defined "polygons." Finally, temperature interfaces were defined with a color chart to produce the image on the back cover as well as those in Fig. 1. The warmest water (red to gold colors at the bottom right) is a component of Atlantic water, more commonly known as the West Spitsbergen Current. The colder (bluer) polar water bathes the continental shelf and nearslope region of Greenland as it exits the Arctic Ocean from the north with a surface layer of sea ice (not shown). As one moves vertically downward in the model (Fig. 1a through c), it becomes readily apparent that much of the warmer Atlantic water never reaches the Arctic Ocean but is recirculated across 


\section{One of the unique}

features to appear

is a deep convective

chimney extending

from the surface to

a depth of well over

$750 \mathrm{~m}$.
Fram Strait to the west. where it then becomes associated with southward flowing polar waters. Using temperature as a quasi-stable tracer (in this specific case, it is not a true conservative property), one can see that only a portion of the inflowing water moves into the Arctic Ocean as a narrow filament that hugs the north coast of Spitsbergen. As the inflowing water loses its heat to the atmosphere, it becomes more dense and sinks to deeper levels. The upper part of a warm core (bottom left of Figs. 1a, 1b and 1c) between the depths of 400 and $500 \mathrm{~m}$ represents the final product of the inflowing Atlantic water after its complete circuit through the Arctic Ocean. From year to year, the variation in the amount of Atlantic water input into the system and the nature of the recirculation paths that it takes may vary. However, what is of interest is that the volume model shows only one consistent recirculation path; namely, that which directly borders on the northern extension of the Greenland Sea gyre. Salinity and density modeling of the same region (not shown) also confirm this basic concept and indicate a previously undocumented circulation pattern found north of Spitsbergen (currently being investigated by three researchers). Further investigation of this data set will give a determination of the amount of heat, mass and salt entering into Fram Strait as well as those percentages that reflect the components of recirculation and Arctic Ocean inflow. Estimates of the amount of heat lost to the atmosphere and surface ice cover and the expansion of the model to deeper levels will also be undertaken.

Examples of near-synoptic mapping of mesoscale features at the Fram Strait MIZ — a highly dynamic frontal region where the ice-covered, polar derived waters meet the warmer, more-saline open oceanrepresent data collected on a much shorter time scale and are shown in Figs. 2 (p. 25 ) and 3 (p. 28). These measurements were obtained from the last phase (April-May 1989) of the recently completed Coordinated Eastern Arctic Research Experiment (CEAREX), sponsored by the Office of Naval Research.

The first model (Fig. 2) is that of an intensive 120 $\mathrm{km}$ by $40 \mathrm{~km}$ XBT (expendable bathythermograph) survey along the edge of the MIZ taken over a period of thirty-six hours. A total of fifty-four $750 \mathrm{~m} \mathrm{XBT}$ probes and 103 sea surface temperature data points (obtained from a hull mounted temperature sensor) were used to create the volumetric model over a defined grid of 20 by 25 by 25 (X, Y and $Z$ respectively). On the eastern vertical-face of the modeled volume, there are two separate cores of warmer Atlantic water (greater than $3^{\circ} \mathrm{C}$ ) located at a depth of $250 \mathrm{~m}$ embedded in a more continuous flow of slightly cooler recirculated water. At the surface, more striking characteristics of the mesoscale features are readily observed. Some warm-core features seem to be more or less isolated. However, upon further investigation of the interior of the model, the Atlantic water tends to be more uniform in nature. with only local outcropping at the surface to create the observed expression. Rotating the model to a more face-on attitude and removing all water with temperatures above $1.8^{\circ} \mathrm{C}$ yields a more dramatic view of the internal construction of the colder component of the volume (Fig. 2b). Volumetric calculations indicate that the volume of water missing (i.e.. greater than $1.8^{\circ} \mathrm{C}$ ) comprises $1648 \mathrm{~km}^{3}$. Removing an additional three layers to show temperatures of less than $0^{\circ} \mathrm{C}$ (Fig. $2 \mathrm{C}$ ) shows the large variations in depth of this layer. One of the unique features to appear is a deep convective chimney extending from the surface to a depth of well over $750 \mathrm{~m}$. The last image (Fig. 2d) overlays the scattered data onto Fig. $2 c$ to show the relative density of information used in the determination of the modeled volume.

Figure 3 represents a 27 -station hydrographic survey of two warm-core mesoscale features nearly surrounded by polar waters, again located at the MIZ. This survey took sixty-four hours to complete, encompassed a region roughly $40 \mathrm{~km}$ by $50 \mathrm{~km}$ by 500 $\mathrm{m}$, and was modeled using a grid structure of 25 by 20 by 20 . Closer inspection of the modeled volume (Fig. 3a) shows that at least three mesoscale features are documented: two nearly-isolated warm-core features seen near the mid-section of the surface face and one nearly-isolated cold-core feature located slightly to the right. The colder polar water occupying the left $30 \%$ of the surface face is a shallow feature, as seen from the left vertical face. From their appearance at the surface, both cold-core features are thernally similar; however, it can be shown that their vertical structures are significantly different. By removing all of the thermal layers with temperature greater than $1.8^{\circ} \mathrm{C}$ and looking into the volume from the front right-side edge (Fig. 3b), two open lobes (a smaller and shallower one to the left and a larger one on the right that extends all the way to the rear vertical face) are seen to be separated by a central column. This column represents a stronger root directly beneath the smaller of the two cold-core feature previously discussed. It also appears that the source of warm water for the larger warm-core feature is from 
the larger lobe to the right of the column. Whether or not the smaller warm-core feature was spalled off the larger warm-core feature or was a separate offshoot of the warmer Atlantic water intrusion cannot be determined. It is apparent, though, that there is an open connection to this smaller feature from the open ocean via the smaller lobe. Inverse perspectives can be created just as easily (in about five seconds) by removing all water having temperatures less than $1.8^{\circ} \mathrm{C}$ (Fig. $3 \mathrm{c}$ ) and then again by removing all layers cooler than $3{ }^{\circ} \mathrm{C}$ (Fig. 3d). These perspectives indicate that the larger warm-core feature may have been created as a by-product of an intrusive jet of Atlantic water.

The previous examples showcase the ability to model, display and analyze randomly spaced field data. Also of interest to researchers is the ability to make use of the display and analysis capabilities on models generated from other sources. In an effort to monitor the water quality of the Chesapeake Bay and its tributaries, the Army Corps of Engineers (ACE) created a primitive-equation model based upon field information collected over an entire year. The images of the estuarine environment of Chesapeake Bay (Fig. 4, p. 29) represent only a small fraction of the results obtained from the computer model. Full volumetric grids of temperature and salinity, representing changes at ninety-minute intervals for the year (nearly 11.000 models in all) were directly converted into IVM compatible grid formats, thereby eliminating the scattered data modeling.

In order to display this amount of data effectively, an animation sequence was created which shows the changes in circulation patterns following periods of major rainfall. The images in Fig. 4 are individual "snapshots" taken from approximately nine hundred display files (one file for each model representing a sixty-day window) which were used for the initial animation sequence. The upper two images are views of the salinity distribution from the full Chesapeake Bay model at Day 300 . shown obliquely from above (Fig. 4a) and below (Fig. 4b). The less saline water of the tributaries is shown in blue, graduating to the more saline water of the bay, shown in brown. The images in Fig. $4 \mathrm{c}$ and $4 \mathrm{~d}$ are close-up views of the upper bay for days 312 and 328, respectively. At Day 312 (Fig. 4c), the intrusion of higher salinity waters into the upper reaches of the bay is shown by the large concentration of brown and gold water masses. The influx of fresh water (blue and purple colors) following substantial rains gradually dilutes and displaces this water mass in Day 328 (Fig. 4d). By studying the flow patterns highlighted by the animation, hydrologists and engineers at $\mathrm{ACE}$ expect to be able to more effectively utilize the water resource and more efficiently respond to emergency situations such as toxic spills.

The images used in this article convey the variety of ways in which three-dimensional modeling of environmental parameters and their subsequent manipulation can be beneficial to the scientist. Unfortunately, static images can never relay the operational characteristics of such a system. The capability of rotating an image, slicing away sections of the model along any of the axes, peeling away modeled layers, zooming into or out of the image-all in nearreal time (roughly three to five seconds per manipulation) - can only be hinted at. These real-time functions enhance the researcher's ability to understand all facets of the complexity of the modeled property space within several hours. The ability to calculate volumes between complex surfaces within userdefined regions can provide information about specific features or water masses that are far more precise than previously generated estimates. Calculation of corresponding property contents such as heat, mass, salt or chemical constituents further enhance the power of three-dimensional modeling as a research tool.

Sophisticated three-dimensional GIS systems, such as IVM, are being actively used by research scientists in a variety of settings, including the oil industry (British Petroleum and Mobil Oil) and government agencies (Aberdeen Proving Ground. Army Corps of Engineers. Office of Surface Mining, U.S. Geological Survey, and Lawrence Livermore National Lab). As with the use of any sophisticated tool. the benefits of three-dimensional modeling and volumetric visualization for studying multi-dimensional data depend upon the ability of the user. Any interpretation of the results of three-dimensional modeling must be based on a critical understanding of not only the spatial and temporal nature of the original data, but also the mathematical concepts that are intrinsic to the modeling process. Given this level of understanding, the ability to model the temporal and spatial information which comprise the complex data collected in the field is a crucial step in the timely and efficient study of the environment from which data were taken. The ability to visually manipulate and gain quantitative information from a full threedimensional model provides more information to the researcher over a significantly shorter period of time than a myriad of cross-sections and planar maps
Unfortunately, our

analysis techniques

typically lag far behind

advances in our means

of acquiring data. 


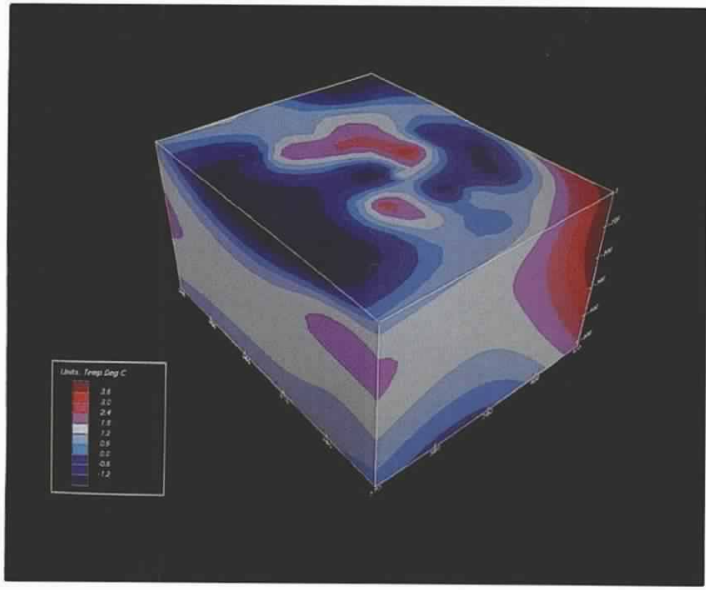

a.

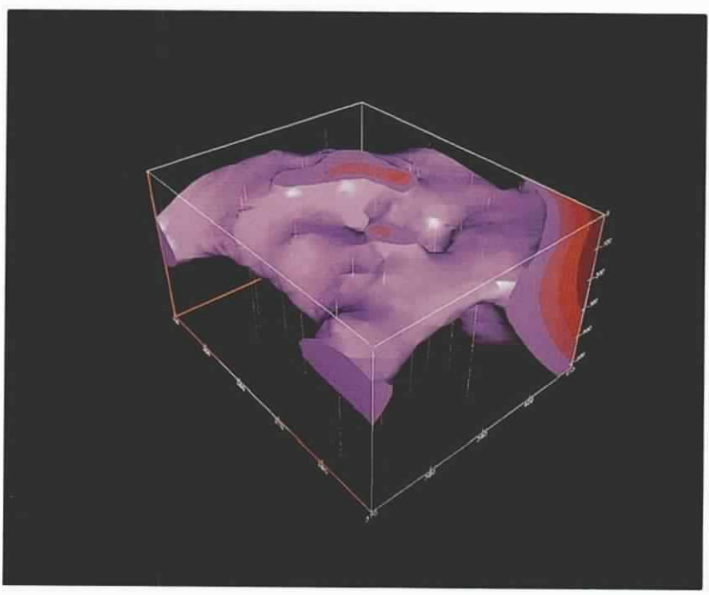

c.

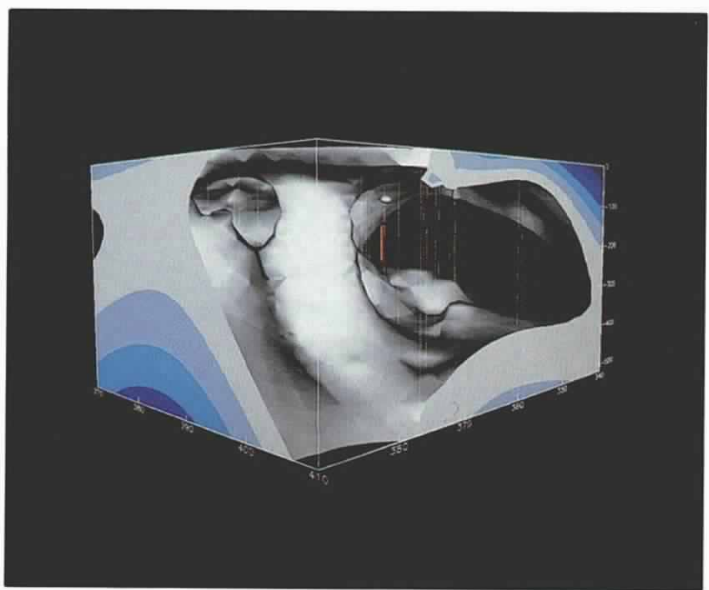

$b$.

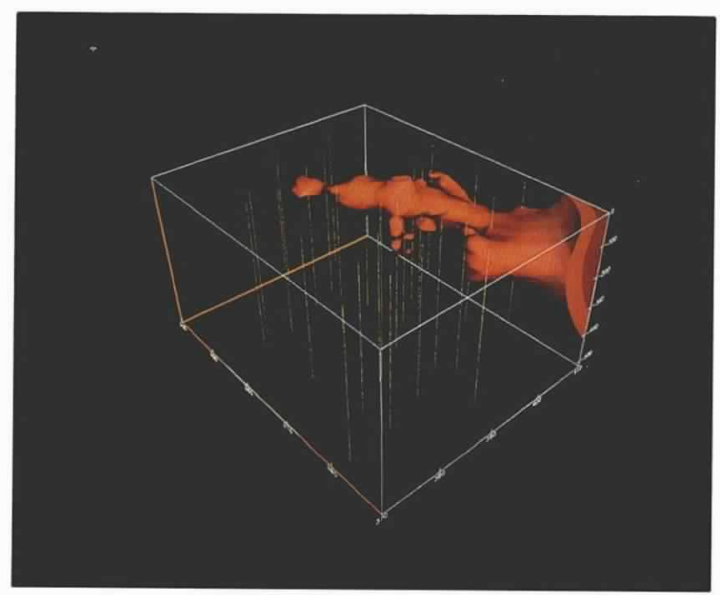

d.

Fig. 3: Modeled volume of temperature obtained from a thirty-station hydrographic survey also taken at the MIZ during the April-May phase of the 1989 CEAREX field program. Color definitions are the same as in Fig. 2. Fig. 3 a shows a single view of the entire modeled volume. Fig. 3 b shows a face-on "on-edge" view (front right hand edge in Fig. $3 a$ ) of the volume, with all water having temperatures greater than $1.8^{\circ} \mathrm{C} \mathrm{removed}$. The central "column" of water is discussed in the text. Data lines were superimposed onto this image. The volume of water removed was $437 \mathrm{~km}^{3}$. Fig. $3 \mathrm{c}$ shows an inverse perspective of Fig. $3 \mathrm{~b}$, but viewed with the same view angle as Fig. 3 a, i.e., all water possessing temperatures less than $1.8^{\circ} \mathrm{C}$ was stripped away. Fig. $3 d$ is the same perspective view as Fig. $3 \mathrm{c}$; however only water having temperature greater than $3^{\circ} \mathrm{C}$ is shown. It is interesting to note the "injected" or "squirt-like" appearance of the Atlantic water.

(assuming they could have been digested at all). In addition, the ability to use such graphic representations to communicate thoughts and ideas among colleagues is equally important.

In the field of oceanography, descriptive and theoretical investigators continue to use sophisticated technology in an effort to learn more about the complex phenomena existing within the oceans. These data gathering and modeling techniques generate tremendous amounts of information which are often input to computers, operated on by sophisticated software, and output for analysis. Unfortunately, our analysis techniques typically lag far behind advances in our means of acquiring data. More powerful computers will simply not solve all our problems, since the use of standard two-dimensional investigative techniques to visually analyze volumetric data falls appreciably short in delivering information to the viewer. Only through the use of three-dimensional GIS tools can we effectively analyze and understand our multi-dimensional data and the environment it represents. 


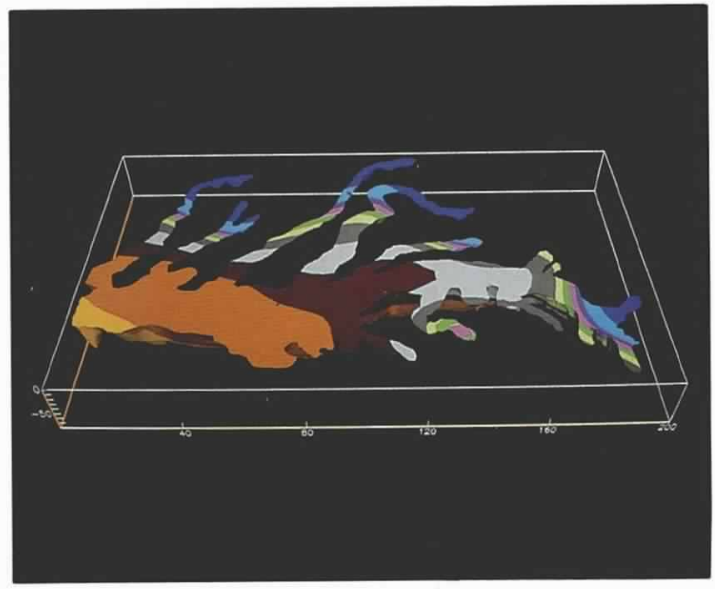

a.

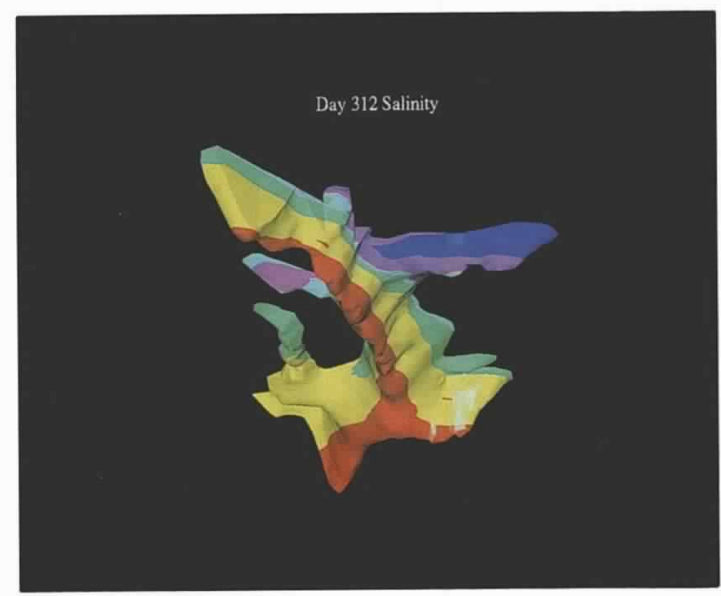

c.

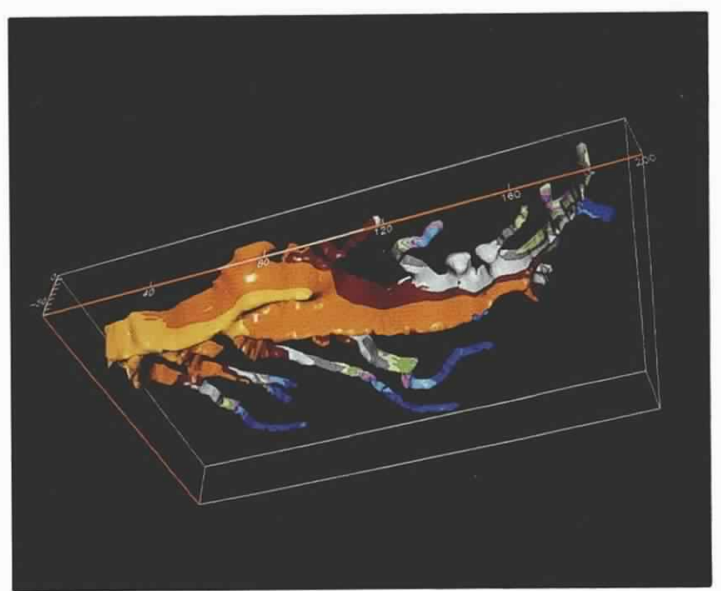

b.

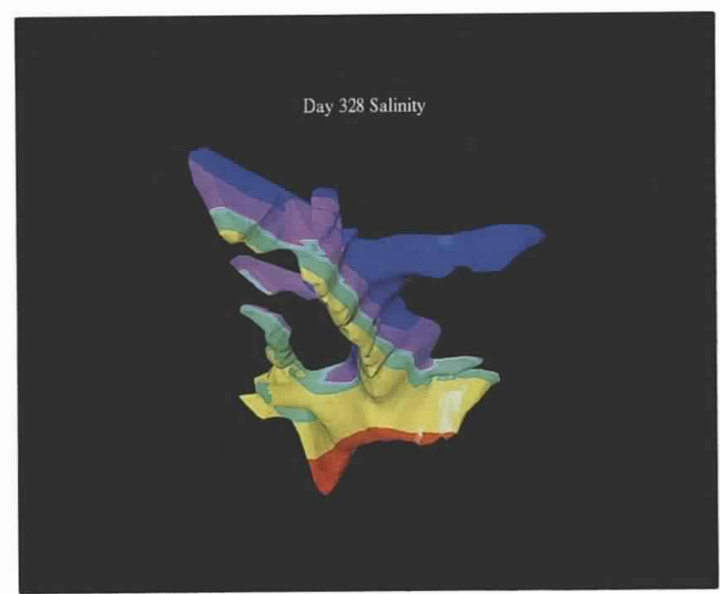

d.

Fig. 4: Images of the estuarine environment of the Chesapeake Bay, depicting changes in circulation patterns as evidenced by changing salinity concentrations following a period of major rainfall. The images are based on results from a primitive-equation numerical model of the bay. Figs. 4 a and $4 \mathrm{~b}$ show the salinity distribution of the entire bay model for Day 300, viewed obliquely from above and below, respectively. The perspective in Figs. $4 b, 4 c$ and $4 d$ shows the water as if viewed from below, i.e., through a transparent bay bottom. Fig. $4 c$ depicts the influx of higher salinity water (brown and gold water masses) into the upper reaches of the bay at Day 312. By Day 328 (Fig. 4d), the higher salinity water is displaced and/or diluted by substantial rains, as shown by the large extent of the blue and purple water masses.

\section{Acknowledgements}

The conversion of both the Fram Strait/CEAREX data sets and the Army Corps of Engineers' Chesapeake model runs, and the creation of the displays, were accomplished by Karen Waldo and Skip Pack of Dynamic Graphics, Inc. (Washington, D. C. and Berkeley, California offices, respectively). All modeling and display of the data was done on the Silicon Graphs Iris 4-D workstation using Interactive Volume Modeling from Dynamic Graphics. Personal thanks are given to Art Paradis, Karen Waldo and
Dennis Smith of Dynamic Graphics who took the time to implement IVM for the field of oceanography, and to Tom Curtin, Program Manager of physical oceanography in the Arctic Sciences Division of the Office of Naval Research, who provided support for this endeavor. This article was completed while Tom Manley was a Research Associate in Geology at Middlebury College and was primarily supported by ONR contract N00014-87-K-204 Scope-MH. This is MRC contribution 02 . $\square$ 